\title{
Genetic variation of Nigerian cattle inferred from maternal and paternal genetic markers
}

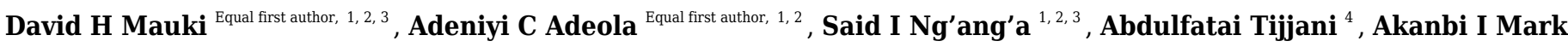 \\ ${ }^{5}$, Oscar J Sanke ${ }^{6}$, Abdussamad M Abdussamad ${ }^{7}$, Sunday C Olaogun ${ }^{8}$, Jebi Ibrahim ${ }^{9}$, Philip M Dawuda ${ }^{10}$, Godwin F \\ Mangbon ${ }^{11}$, Paul S Gwakisa ${ }^{12}$, Ting-Ting Yin ${ }^{1}$, Min-Sheng Peng ${ }^{1,2,3}$, Ya-Ping Zhang ${ }^{\text {Corresp. } 1,2,3,13,14}$ \\ ${ }^{1}$ State Key Laboratory of Genetic Resources and Evolution, Kunming Institute of Zoology, Chinese Academy of Sciences, Kunming, Yunnan, China \\ 2 Chinese Academy of Sciences, Sino-Africa Joint Research Center, Kunming, Yunnan, China \\ 3 University of Academy of Sciences, Kunming College of Life Science, Kunming, Yunnan, China \\ 4 School of Life Sciences, University of Nottingham, Nottingham, United Kingdom \\ 5 Ministry of Agriculture and Rural Development, Secretariat, Ibadan, Oyo, Nigeria \\ 6 Taraba State Ministry of Agriculture and Natural Resources, Jalingo, Taraba, Nigeria \\ 7 Department of Animal Science, Faculty of Agriculture, Bayero University, Kano, Kano, Nigeria \\ 8 Department of Veterinary Medicine, University of Ibadan, Ibadan, Oyo, Nigeria \\ 9 College of veterinary medicine, department of theriogenology, University of agriculture, Makurdi, Makurdi, Benue, Nigeria \\ 10 Department of Veterinary Surgery and Theriogenology, College of Veterinary Medicine, University of Agriculture Makurdi, Makurdi, Benue, Nigeria \\ 11 Division of Veterinary Office, Serti, Taraba, Nigeria \\ 12 Department of Microbiology, Parasitology and Biotechnology/ Genome Science Center, Sokoine University of Agriculture, Morogoro, Tanzania \\ 13 State Key Laboratory for Conservation and Utilization of Bio-Resource in Yunnan, School of Life Sciences, Yunnan University, Kunming, Yunnan, China \\ 14 Center for Excellence in Animal Evolution and Genetics, Chinese Academy of Sciences, Kunming, Yunnan, China
}

Corresponding Author: Ya-Ping Zhang

Email address: zhangyp@mail.kiz.ac.cn

The African cattle provide unique genetic resources shaped up by both diverse tropical environmental conditions and human activities, the assessment of their genetic diversity will shade light on the mechanism of their remarkable adaptive capacities. We therefore analyzed the genetic diversity of cattle samples from Nigeria using both maternal and paternal DNA markers. Nigerian cattle can be assigned to 80 haplotypes based on the mitochondrial DNA (mtDNA) D-loop sequences and haplotype diversity was $0.985+0.005$. The network showed two major matrilineal clustering: the dominant cluster constituting the Nigerian cattle together with other African cattle while the other clustered Eurasian cattle. Paternal analysis indicates only zebu haplogroup in Nigerian cattle with high genetic diversity $1.000 \pm 0.016$ compared to other cattle. There was no signal of maternal genetic structure in Nigerian cattle population, which may suggest an extensive genetic intermixing within the country. The absence of Bos indicus maternal signal in Nigerian cattle is attributable to vulnerability bottleneck of mtDNA lineages and concordance with the view of male zebu genetic introgression in African cattle. Our study shades light on the current genetic diversity in Nigerian cattle and population history in West Africa.

Peer) reviewing PDF | (2020:06:50178:2:1:NEW 26 Nov 2020) 
1 Genetic variation of Nigerian cattle inferred from maternal and paternal genetic markers

2

3 David H Mauki Equal first author, 1, 2, 3, Adeniyi C Adeola Equal first author, 1, 2, Said I Ng'ang'a 1, 2, 3 , 4 Abdulfatai Tijjani ${ }^{4}$, Akanbi I Mark ${ }^{5}$, Oscar J Sanke ${ }^{6}$, Abdussamad M Abdussamad 7 , Sunday C

5 Olaogun $^{8}$, Jebi Ibrahim ${ }^{9}$, Philip M Dawuda ${ }^{10}$, Godwin F Mangbon ${ }^{11}$, Paul S Gwakisa ${ }^{12}$, Ting-Ting 6 Yin $^{1}$, Min-Sheng Peng 1, 2, 3, Ya-Ping Zhang ${ }^{1,2,3,13,14, *}$

7

$8{ }^{1}$ State Key Laboratory of Genetic Resources and Evolution, Kunming Institute of Zoology,

9 Chinese Academy of Sciences, Kunming, Yunnan, China.

$10{ }^{2}$ Chinese Academy of Sciences, Sino-Africa Joint Research Center, Kunming, Yunnan, China.

$11{ }^{3}$ University of Academy of Sciences, Kunming College of Life Science, Kunming, Yunnan,

12 China.

$13{ }^{4}$ School of Life Sciences, University of Nottingham, Nottingham, United Kingdom.

$14{ }^{5}$ Ministry of Agriculture and Rural Development, Secretariat, Ibadan, Oyo, Nigeria.

$15{ }^{6}$ Taraba State Ministry of Agriculture and Natural Resources, Jalingo, Taraba, Nigeria.

$16{ }^{7}$ Department of Animal Science, Faculty of Agriculture, Bayero University, Kano, Nigeria.

$17{ }^{8}$ Department of Veterinary Medicine, University of Ibadan, Ibadan, Oyo, Nigeria. 
$18{ }^{9}$ College of veterinary medicine, department of theriogenology, University of agriculture,

19 Makurdi, Makurdi, Benue, Nigeria.

$20{ }^{10}$ Department of Veterinary Surgery and Theriogenology, College of Veterinary Medicine,

21 University of Agriculture Makurdi, Makurdi, Benue, Nigeria

$22{ }^{11}$ Division of Veterinary Office, Serti, Taraba, Nigeria.

$23{ }^{12}$ Department of Microbiology, Parasitology and Biotechnology/ Genome Science Center, Sokoine

24 University of Agriculture, Morogoro, Tanzania.

$25{ }^{13}$ State Key Laboratory for Conservation and Utilization of Bio-Resource in Yunnan, School of

26 Life Sciences, Yunnan University, Kunming, Yunnan, China.

$27{ }^{14}$ Center for Excellence in Animal Evolution and Genetics, Chinese Academy of Sciences,

28 Kunming, Yunnan, China.

$29 *$ Corresponding Author: Ya-Ping Zhang

30 Email address: zhangyp@mail.kiz.ac.cn

\section{Abstract}

33 The African cattle provide unique genetic resources shaped up by both diverse tropical

34 environmental conditions and human activities, the assessment of their genetic diversity will

35 shade light on the mechanism of their remarkable adaptive capacities. We therefore analyzed the

36 genetic diversity of cattle samples from Nigeria using both maternal and paternal DNA markers.

37 Nigerian cattle can be assigned to 80 haplotypes based on the mitochondrial DNA (mtDNA) D- 
38 loop sequences and haplotype diversity was $0.985 \pm 0.005$. The network showed two major

39 matrilineal clustering: the dominant cluster constituting the Nigerian cattle together with other

40 African cattle while the other clustered Eurasian cattle. Paternal analysis indicates only zebu

41 haplogroup in Nigerian cattle with high genetic diversity $1.000 \pm 0.016$ compared to other cattle.

42 There was no signal of maternal genetic structure in Nigerian cattle population, which may

43 suggest an extensive genetic intermixing within the country. The absence of Bos indicus

44 maternal signal in Nigerian cattle is attributable to vulnerability bottleneck of mtDNA lineages

45 and concordance with the view of male zebu genetic introgression in African cattle. Our study

46 shades light on the current genetic diversity in Nigerian cattle and population history in West

47 Africa.

49 Keywords: mtDNA, Y-chromosome, genetic diversity, Nigerian cattle, West Africa

\section{INTRODUCTION}

52 The modern domestic cattle were initially domesticated about 10,000 years ago from two putative

53 domestication centers, the Near East for Bos taurus and the Indian Sub-continent for B. indicus

54 (Loftus et al., 1994a). In Africa, the modern domestic cattle were probably introduced at different

55 times with B. taurus circa 7,000-4,000 years BP and B. indicus circa 4,000-2,000 years BP

56 from their putative centers of domestication (Meghen, MacHugh \& Bradley, 1994; Freeman et al.,

57 2004). However, the zebu cattle were also reintroduced to the African continent by Arab traders

58 around $\sim 699$ - 640 years AD following the death of the Prophet (Bradley et al., 1998). Penetration

59 of the predominant African taurine to West Africa was amid 4,000 years BP (Marshall \& 
60 Hildebrand, 2002). The post-introduction of the zebu cattle led to their spread sporadically to

61 West Africa circa 1,400 years ago (Meghen, MacHugh \& Bradley, 1994; Hanotte et al., 2002)

62 from East Africa hypothesized to be the original entry point of zebus in Africa (Gifford-Gonzalez

$63 \&$ Hanotte, 2011). To date, the origin and migration of ancient and modern African cattle is still

64 under strong debate due to conflicting archaeological and genetic evidence (Hanotte et al., 2000,

65 2002; Magnavita, 2006), therefore, unravelling of any possible clues is still at large and with very

66 crucial pressure sought-after by scientist and archaeologist.

67 In the past decade scientist have been using mtDNA markers in the control region and the entire

68 mtDNA genome to understand phylogenetic tree models for describing origin, divergence times

69 and domestications of cattle and their population expansion to different parts of the globe (Achilli

70 et al., 2008; Ho et al., 2008; Horsburgh et al., 2013; Olivieri et al., 2015). MtDNA studies on

71 cattle have grouped them in two major lineages represented by haplogroup T for B. taurus (Troy et

72 al., 2001) and haplogroups I1 and I2 (Chen et al., 2010) both defining the genetic lineage of $B$.

73 indicus. Within the haplogroup T, sister sub-haplogroups T1, T2, T3, T4 and T5 were revealed

74 (Mannen et al., 2004; Achilli et al., 2008, 2009). The haplotypes T2 and T3 are the dominant

75 haplotypes in the Middle East and Europe and also in Africa at very low frequency (Beja-Pereira

76 et al., 2006; Olivieri et al., 2015). Majority of the mtDNA haplotypes in African cattle are defined

77 by T1 haplogroup (Troy et al., 2001; Horsburgh et al 2013), with no evidence of zebu mtDNA

78 haplotypes been reported so far. There has been some more discoveries of other haplotypes P, Q,

79 R, E and C especially when analysis of whole mtDNA genome was applied (Achilli et al 2008,

80 2009; Bonfiglio et al., 2010), with only haplotype Q (Q1) being reported recently in the African

81 cattle (Olivieri et al., 2015). 
82 Genetic studies on paternal Y-chromosomal DNA markers have previously reported the frequency

83 of both haplogroups Y1 and Y2 for taurines and of Y3 haplogroup an exclusive for zebus

84 (Götherström et al., 2005; Bonfiglio et al., 2012b; Ginja et al., 2010). Some authors like Perez-

85 Pardal et al. (2010), Alvarez et al. (2017) and Chen et al. (2018) have reported both Y1 and Y2

86 haplotype frequencies in sub-Saharan and Mediterranean regions in modern African cattle at

87 considerable varying frequencies. However, majority of the African cattle have been reported to

88 be more of zebu background (Hanotte et al., 2000) solely defined by haplogroup Y3 and are

89 distributed at much higher frequency than Y1 or Y2, enormously across Africa encompassing both

90 the North, West, East, Central and southern African regions (Perez-Pardal et al., 2010, 2018;

91 Alvarez et al., 2017; Ginja et al., 2019).

92 Nigeria, a country in West Africa harbors both the taurine and zebu cattle (Rege, 1999) and their

93 crossbreds (Loftus et al., 1994a). Apart from their economic benefit such as meat, milk, and skin,

94 the Nigerian cattle are observed as important idols in ceremonial rituals and also utilized in

95 drafting and ploughing during farming. Acquisition of the current knowledge regarding the genetic

96 status of Nigerian cattle is crucial for conservation and utilization of their genetic resources.

97 Previous genetic diversity studies in West African cattle, particularly in Nigeria are limited by the

98 few number of populations (Bradley et al., 1994; Loftus et al., 1994a; Loftus et al., 1994b;

99 Bradley et al., 1996; Perez-Pardal et al., 2018). This could imply that the actual extent of the

100 genetic diversity of Nigerian cattle still remains an enigma.

101 To disclose the genetic diversity in Nigerian cattle, we employed the use of both mtDNA and Y-

102 chromosomal markers, which have been widely used in assessing the diversity and

103 phylogeographic structure of many domestic animals (Lindgren et al., 2004; Ramirez et al., 2009;

104 Wang et al., 2014; Alvarez et al., 2017). In this study, we evaluated variation in the mtDNA D- 
105 loop and Y-chromosome using 139 Nigerian cattle samples. Due to the nature of husbandry

106 management in most of African countries, the assessment of genetic variation in Nigerian cattle

107 was conducted based on their sampled locations such as from North western (Zamfara, Kano,

108 Katsina, Kaduna, and Sokoto States); North eastern/central (Taraba, and Plateau States) and

109 western (Oyo State) regions of Nigeria (Fig. 1a).

\section{MATERIALS AND METHODS}

\section{Ethical considerations}

112 All experimental procedures in the present study were performed in accordance to Research

113 Guidelines for the Institutional Review Board of Kunming Institute of Zoology, Chinese

114 Academy of Sciences (SMKX2017009) and the Central Abattoir, Ibadan, Ministry of

115 Agriculture and Rural Development, Oyo State, Nigeria. Several cattle are usually transported

116 from farms in different states in Nigeria to the Central Abattoir in Ibadan. Therefore, all cattle

117 samples were then collected at the Central Abattoir, Ibadan.

\section{Sampling and data collection}

119 A total of 139 Nigerian cattle individuals (119 females and 20 males) were sampled from 120 farmer's herds in eight different States in Nigeria as follows (Fig. 1a); Kaduna State (n=19

121 females; $n=3$ males), Kano State ( $n=4$ females; $n=2$ males), Katsina State ( $n=4$ females; $n=2$

122 males), Sokoto State ( $n=27$ females; $n=4$ males), Mambilla plateau in Taraba State $(n=35$

123 females; $n=2$ males), Zamfara State ( $n=8$ females; $n=2$ males), Oyo State ( $n=1$ female; $n=2$

124 males) and Jos city in Plateau State ( $n=21$ females; $n=2$ males). During sample collection,

125 genetically unrelated cattle from the eight states in Nigeria, ecological and geographical

126 perspectives were considered. This included randomly sampling of at least two animals per 
127 household and only from those households located approximately $0.5 \mathrm{~km}$ further apart. Farmers

128 were also interviewed on the pedigree information of their animals prior to carrying out blood

129 collection. Blood samples were kept in $95 \%$ ethanol at room temperature before transportation to

130 the laboratory. Samples were stored at $4^{\circ} \mathrm{C}$ for immediate use, or at $-80^{\circ} \mathrm{C}$ for later use.

131 Yak (Bos grunniens: Accession no. MN398192, Huang et al., 2020), was used as an outgroup in

132 phylogenetic tree analysis. A total of 420 sequences based on $636 \mathrm{bp}$ (of the D-loop region) that

133 included 119 individuals from Nigeria, 76 from Europe, 16 from West Asia, and 209 from other

134 African countries (31 Egyptian cattle, 16 Mozambiquan cattle, 126 Ethiopian cattle, 34 Nguni

135 cattle from South Africa, and two additional samples from Nigeria) were used in mtDNA

136 analyses (more information in Figure 1 legend part b; Table S1a). For Y-chromosome analyses

137 only few representative samples of the three major haplogroups of cattle were used as detailed in 138 supplementary Table S2.

139 DNA extraction, PCR and sequencing

140 Genomic DNA was extracted from $\sim 5 \mathrm{ml}$ of blood following phenol-chloroform method

141 (Sambrook \& Russell, 2001). We amplified 636-base pair of the D-loop region of mtDNA, using

142 primers constructed from L27712 D-loop sequence for both forward and reverse primers (Table

143 S3) (Loftus et al., 1994a). The mtDNA amplification and sequencing reactions were carried out in

144 a total of $25 \mu \mathrm{l}$ PCR reaction mixture using $\sim 40 \mathrm{ng}$ of mtDNA, 10 pmol of each primer, $2.5 \mathrm{mM}$

145 dNTPs and 5 units of Takara Taq DNA polymerase in a 10 pmol reaction buffer containing 1.5

$146 \mathrm{mM} \mathrm{MgCl} 2$. Amplifications were carried out in a thermocycler for at least 35 cycles as follows:

$14795^{\circ} \mathrm{C}$ for $5 \mathrm{~min}, 94^{\circ} \mathrm{C}$ for $45 \mathrm{sec}, 58^{\circ} \mathrm{C}$ for $30 \mathrm{sec}, 72^{\circ} \mathrm{C}$ for $1 \mathrm{~min} 30 \mathrm{sec}$, and a final extension of 7

$148 \min$ at $72^{\circ} \mathrm{C}$. The quality and confirmation check were performed using $2 \%$ agarose gel and

149 visualization under UV transilluminator. 
150 We have sequenced $286 \mathrm{bp}$ of the bovine Y-chromosome in 20 Nigerian cattle (Table S2 and S3)

151 in order to identify polymorphic sites in the X-degenerate male specific regions of the bovine $\mathrm{Y}$ -

152 chromosome (MSY) (Chang et al., 2013). In particular, a region of the zinc finger protein Y-

153 linked (ZFY) gene similar to that of Homo sapiens (human) intron 10 was used as previously

154 described (Ginja, Telo da Gama \& Penedo, 2009; Table S3) for the amplification and sequencing

155 of all 20 samples at the length of $286 \mathrm{bp}$. We applied the same PCR conditions used in the

156 amplification of mtDNA with exceptional of the annealing temperature of $53^{\circ} \mathrm{C}$. The quality

157 control checks as described in mtDNA were also carried out on all the 20 PCR amplicons. The

158 amplified mtDNA and Y-chromosomal DNA fragments were subjected to sequencing procedures

159 such as purification of the PCR products with Exo - SAP-IT Cleanup kit as per manufacturer's

160 instructions (Affymetrix). Subsequently, sequencing reactions were carried out using the

161 BigDye $^{\mathrm{TM}}$ Terminator v3.1 Cycle Sequence Kit (Applied Biosystems) and the generated products

162 from this step were further purified by alcohol precipitation. Lastly, we used ABI PRISM 3730

163 automated DNA sequencer (Applied Biosystems) to sequence the purified products. All

164 sequences were assembled in SeqMan Lasergene package in DNASTAR software.

\section{Data analysis}

\section{Sequences check and alignment}

167 The assembled DNA sequences of 139 individuals were exported into MEGA X ver 10.1.7

168 software (Kumar et al., 2018) for alignment with other cattle populations mined from Genbank

169 for both mtDNA D-loop (Table S1a and S1b) and ZFY Y-chromosomal markers (Table S2).

170 Multiple sequence alignments of the D-loop region and ZFY gene of the Y-chromosome were

171 carried out using CLUSTAL W package (Thompson, Higgins \& Gibson, 1994) integrated in the 
172 MEGA software. All sites containing alignment gaps were excluded from the analysis. Our data

173 involved amplification and sequencing of the 636 -base pair (bp) mtDNA D-loop region and 286

174 bp ZFY gene of 119 and 20 Nigerian cattle samples respectively. Variations in the D-loop region

175 were detected by assembling all forward and reverse sequences against the reference $B$. taurus

176 mtDNA sequence [(GenBank accession no. V00654); (Anderson et al., 1982)]. Variations in the

177 Y-chromosome of the X degenerate region located at intron 10 of ZFY gene were also

178 determined. The alignments and assembly of the Y-chromosome sequences were carried out

179 similarly following the protocol used by Ginja, Telo da Gama \& Penedo, (2009) where

180 sequences from distantly related species were used as described by Götherström et al. (2005) but

181 using Bison bison, Bos frontalis, and B. grunniens sequences (Verkaar et al., 2004). The

182 polymorphic sites in the $\mathrm{Y}$ - chromosome male specific region were identified using a $\mathrm{Y}$ -

183 chromosome B. taurus reference genome (GenBank Accession no. AF241271; Lawson et al., 184 2002).

\section{Genetic diversity and haplogroup classification}

186 MitoToolPy_Linux (Peng et al., 2015) was used to determine haplogroup distribution across

187 Africa by analyzing a 240 bp fragment length of the D-loop region of mtDNA involving 609

188 cattle samples in total (including the 119 Nigerian cattle sequenced in this study [(Fig. 1a; Table

189 S1b); (reference data were retrieved from: Loftus et al., 1994a; Bradley et al., 1996; Troy et al.,

190 2001; Beja-Pereira et al., 2006; Dadi et al., 2009; Bonfiglio et al., 2012a; Horsburgh et al.,

191 2013; Olivieri et al., 2015)]. We used DnaSP v5 (Librado \& Rozas, 2009) to determine the

192 haplotypes in $420 \mathrm{mtDNA}$ cattle sequences and the assignment of bovine Y-chromosome

193 haplogroups for Nigerian cattle. Genetic diversity, was assessed by using Arlequin v3.5

194 (Excoffier \& Lischer, 2010) and expressed in terms of the total number of haplotypes (H) and 
195 polymorphic sites (PS), haplotype diversity (HD), nucleotide diversity $(\pi)$, the mean number of

196 nucleotide differences (Df) and their standard deviations (SD) estimated across all African

197 populations used in this study. Notably, the comparisons of the genetic diversity estimates were

198 considered for only those populations with sample size above 5.

\section{Phylogenetic tree analyses}

200 To investigate the evolutionary relationship of Nigerian cattle with other cattle samples mined

201 from GenBank (Table S1a and S2), the same version of MEGA software was used to construct a

202 rooted neighbor-joining (NJ) phylogenetic tree (Saitou \& Nei 1987) using the Maximum

203 Composite Likelihood evolutionary distance approach (Tamura, Nei \& Kumar, 2004) and

204 bootstrap test was employed at 1000 replications so as to assess the confidence of each node

205 (Felsenstein, 1985). To further visualize the genetic relationships between the haplotypes and

206 identifying the number of unique mtDNA D - loop haplogroups present in the 420 dataset, the

207 median - joining (MJ) network (Bandelt, Forster \& Rohl, 1999) was generated by using the

208 default setting weights of both transversions and transitions as implemented in Network v4.6

209 software (www.fluxus-engineering.com).

\section{Population genetic structure and demographic dynamic profiles}

211 To infer the matrilineal genetic variation within populations, among populations, and groups of

212 populations, analysis of molecular variance (AMOVA) was carried out following 50,000

213 permutations in Arlequin v3.5 software. The analysis was conducted for Nigerian cattle at

214 various hierarchical levels viz the Nigerian cattle as a single cluster, Nigerian cattle vs the other

215 African countries but also vs cattle from Europe and West Asia. The levels of significance in 
216 each hierarchical cluster tested were evaluated using $\mathrm{F}_{S T}$ parameter at a significant $P$ level of 2170.05.

218 To investigate the population dynamics and demographic patterns of Nigerian cattle population, 219 mismatch distribution patterns were estimated (Rogers \& Harpending, 1992) with respect to 220 their geographical regions for North West and North East. The chi - square test of goodness of

221 fit and Harpending's raggedness index " $r$ " (Harpending, 1994) statistics were also calculated to 222 assert the significance of the deviations of the sum of squares differences (SSD) observed from 223 the simulated model of demographic expansions determined by 1,000 coalescent simulations.

224 Demographic statistical parameters for Tajima's $D$ (Tajima, 1989) and Fu's $F_{\mathrm{S}}(F u, 1997)$ were 225 also estimated by using Arlequin v3.5 software to further complement the mismatch distribution 226 patterns.

\section{RESULTS}

229

230

231

232

234

236

237

\section{MtDNA genetic diversity}

In this study we evaluated variations in the mtDNA D-loop of 119 Nigerian cattle together with 301 global cattle sequences based on 636 bp from Egypt, Ethiopia, Mozambique, South Africa, Europe and West Asia available in the GenBank. The sequences generated in this study have been deposited in the GenBank with accession numbers MT362777 - MT362895. There were 153 variable sites scored in all 420 cattle samples that defined 275 haplotypes (Table S4) and 80 of them assigned to Nigerian cattle sequenced in this study (Table 1). Most of the Nigerian cattle in the current study possess unique haplotypes $(80 \%)$ and the remaining ones were shared with other African and European cattle. The lowest level of haplotype diversity $(0.983 \pm 0.009)$ was 
238 observed in cattle from North East while the highest $(0.984 \pm 0.007)$ was observed in the North

239 Western region. Estimated haplotype diversity (HD) across all Nigerian individuals was

$240 \quad 0.985+0.005$ (Table 1). This value observed is lower than the haplotype diversity of Egyptian

241 and Mozambican cattle populations but was higher compared to Ethiopian and South African

242 cattle.

\section{Haplogroup classification and phylogenetic trees using mtDNA}

244 The haplogroup distribution across Africa shows the majority of African cattle are of B. taurus

245 T1 the widely known B. taurus haplogroup for African cattle (Fig. 1a, Table S1b). The Nigerian

246 cattle in this study were all classified into haplogroup T1 (Table S1a and S1b), and majority of

247 them constitute of haplogroup T1a similar to findings by Olivieri et al. (2015). Apart from

248 Nigeria, other African countries in the Northern part of Africa particularly Egypt, Libya and

249 Morocco also carried other types of B. taurus haplogroups T2, T3 and Q1. No traces of maternal

250 lineages were observed in Nigerian cattle samples sequenced in this study.

251 To obtain further insights into the haplotype relationships, the network analysis (Fig. 1b) and

252 phylogenetic tree (Fig. S1) were constructed using the 636 bp sequences of 119 Nigerian cattle

253 and 301 other sequences retrieved from the GeneBank. The phylogenetic tree depicted two major

254 lineages of cattle, B. taurus (T1, T2, T3, T5, and Q1) and B. indicus (I1 and I2) lineages as

255 expected (Chen et al., 2010; Achilli et al., 2008). All Nigerian cattle have been placed together

256 with the rest of taurine cattle individuals separately from the zebu cattle. The MJ network

257 depicted similar pattern where haplogroup I1 for zebu lineage was separated from all the taurine

258 haplogroups. Furthermore, the network revealed two major clustering: the first cluster showed

259 grouping of Nigerian cattle with African and European cattle; while the second cluster did not

260 contain Nigerian individuals. Cattle samples in the first cluster exhibit a star-like pattern, a 
261 matrilineal characteristic which signifies a signature of population expansion. Furthermore, we

262 found two Nigerian individuals which showed interesting results. These individuals have been

263 placed within the monophyletic clade containing individuals of haplogroups T1, T5 and Q1 from

264 Europe, which could indicate a similar pattern of origin with European cattle (Achilli et al.,

265 2008). One of the individuals (71_TAR_NIG) possess similar mutations as T5 (Achilli et al.,

2662008 ) at g.16255 and 16197 (Table S5) which concurs with the phylogenetic tree results. The

267 second individual (111_KAD_NIG) appears like a basal lineage to this monophyletic clade

268 where individuals of haplogroups T5, T1 and Q1 are clustering. Our analysis also shows some

269 shared polymorphism between Nigerian cattle (71_TAR_NIG and 111_KAD_NIG), the Bison

270 bison and B. grunniens at transitional mutations G/A: g.15921 and T/C: g.16204 (Table S5) as

271 previously detected by (Achilli et al., 2008).

\section{Population genetic structure and historical demographic dynamics}

273 AMOVA analysis incorporating the eight populations from Nigeria showed that more than $99 \%$

274 of the total genetic variation present in Nigerian cattle occurred within individuals (Table S6).

275 Furthermore, when analyzing the genetic variation between Nigerian cattle and other cattle

276 populations AMOVA showed that, 62 to $93 \%$ of the total variation between Nigerian cattle and

277 other African cattle populations occurs within individuals, with the highest variation observed

278 between Nigerian and Mozambican cattle (93.46\%). Generally, all attempts to explore the

279 differentiation between Nigeria and other populations were attributable to within-population

280 variance $(P<0.05)$ with exceptional of variation among populations within groups for Nigerian

281 and European cattle $(\mathrm{F}=0.07375, P=0.00004)$. The $\mathrm{F}_{S T}$ distance values between most Nigerian

282 cattle sub-populations were low (Table S7). However, it was considerably high between Nigerian

283 cattle and other African cattle populations showing significant genetic variation between them at 
$284 P<0.05$ with exceptional for cattle populations between Ethiopia and Mozambique $(\mathrm{FST}=$ -

$2850.00548, P=0.57129)$. Our AMOVA results complemented by genetic distance estimates

286 suggest general absence of maternal genetic structuring in Nigerian cattle sub-populations, likely

287 due to extensive genetic intermixing within the country.

288 To elucidate the demographic dynamics of Nigerian cattle, mismatch distribution patterns, for

289 each geographical region in Nigeria were assessed (Fig. S2). The mismatch distribution patterns

290 were unimodal, however the pattern deviated significantly from expected under a null hypothesis

291 model of either spatial or demographic expansion due to significant values obtained for Sum of

292 Squared deviation (SSD) and Harpending's Raggedness index (HRI) (Table S8). The significant

293 values for SSD and HRI indicate a bad goodness of fit test, which does not support the scenario

294 of population expansion. The values for Tajima's $D-2.315(\mathrm{P}<0.05)$ and Fu's $F_{\mathrm{S}}$ statistics -

$29526.203(\mathrm{P}<0.05)$ on the other hand were both negative and significant indicating an agreement

296 of recent population growth and expansion respectively. Cattle population from Western region

297 part of Nigeria showed Tajima's $D$ value of 0 possibly due to only 3 individuals were sampled,

298 which might indicate that the population in that region evolved as per mutation drift equilibrium

299 with no evidence of selection.

300 Genetic polymorphism of Y-chromosome and haplogroup distribution

301 In supplementary Figure 3, we provide detailed information on haplogroup distribution based on

302 Y-chromosomal markers in Africa (Perez-Pardal et al., 2018; Ginja, Telo da Gama \& Penedo,

303 2009). The sequences generated in this study have been deposited in the GenBank with accession

304 numbers MW284951- MW284970. Our results show that all Nigerian cattle belong to

305 haplogroup Y3 solely a B. indicus haplogroup due to similar mutations (Table 2, Supplementary

306 Data S1). Notably, in addition to previously reported mutations that further classify zebu cattle 
307 into haplotype Y3 families as pointed out by Chen et al. (2018) and Perez-Pardal et al. (2018),

308 we also show new mutations in Nigerian cattle possibly not previously reported. These include

309 those SNPs observed between g.784 and g.805bp (Table 2, Supplementary Data S1). Multiple

310 sequence alignment with haplotypes defining the three major haplogroups of cattle (Y1, Y2 and

311 Y3) (Nijman et al., 2008; Ginja, Telo da Gama \& Penedo, 2009 and Table S2) revealed the

312 existence of seven mutations including mutations $A>G, T>C$ and $T>G$ that distinguish $Y 3 a$ (or

$313 \mathrm{Y}_{\mathrm{C}}$ ) and $\mathrm{Y} 3 \mathrm{~b}\left(\right.$ or $\mathrm{Y} 3_{\mathrm{A}}, \mathrm{Y} 3_{\mathrm{B}}$ ) haplotype families (Table 2) grouping Nigerian cattle into zebu $\mathrm{Y} 3 \mathrm{~b}$

314 sub-haplotype family (Supplementary Data S1) due to having similar polymorphic information at

315 sites A/A and T/T (Supplementary Data S1). Majority of the Nigerian cattle shared haplotype

316 Hap_7Y3 together with cattle from Asia (Fig. 2) which may signify possible shared origin from

317 the most recent common ancestor (TMRCA). The phylogenetic tree shows that Nigerian cattle

318 cluster separately from European Y1 or Y2 haplogroups (Fig. S4). The phylogenetic tree showed

319 some of the Nigerian cattle clustering together with B. grunniens (yak) and B. bison, these two

320 latter populations are considered distantly related populations to the major lineages of domestic

321 cattle (Fig. S4) s

322 The overall genetic diversity for Nigerian cattle measured by the haplotype diversity and the

323 mean number of pairwise difference is $1.000 \pm 0.016$ and $1.679 \pm 1.027$ respectively (Table S9).

324 The genetic diversity detected in some African cattle populations/breeds as per Perez-Pardal et

325 al. (2018) and Ginja, Telo da Gama \& Penedo, (2019) although different Y-chromosomal

326 markers such as microsatellite markers were used, the estimates still provide reliable information

327 needed for comparison with our samples (Table S9). 
330 In this study we examined the genetic variation across eight Nigerian cattle populations, which

331 represent samples from one country in West Africa. The results based on mtDNA D-loop revealed

33280 haplotypes from 119 Nigerian cattle sequences, which showed a haplotype diversity of

$3330.985 \pm 0.005$. The haplotype diversity in Nigerian cattle is lower compared to those of Egyptian

334 cattle $\mathrm{H}=1.0 \pm 0.008$ (Olivieri et al., 2015). These findings signify a high level of maternal

335 genetic variation in Nigerian cattle. AMOVA on the other hand suggests a general absence of

336 maternal genetic structuring in Nigerian cattle that may have been as a result of extensive genetic

337 intermixing within the country. Studies show that genetic intermixing is caused by rigorous

338 transportation of domestic animals like goats, cattle, and sheep from place to place as a result of

339 their valuable resource for economic trade or cultural exchange (Tarekegn et al., 2018). Notably,

340 recent study has revealed the impact of African cattle pastoralism in admixture of cattle across the

341 continent, and this admixture or intermixing has been well observed in the African humped cattle

342 (Kim et al., 2020). It is generally known that most of the genetic variation in cattle elucidated by

343 matrilineal genetic information is attributable to geographical differences (Hanotte et al., 2002),

344 which can be sourced at the regional or continental levels (Dadi et al., 2009) rather than by their

345 morphological disparities or differences in their origins (Alvarez et al., 2017). We observed this

346 scenario in our study samples where the variation was explained only within populations from

347 different geographical regions in Africa such as between pairs of Nigerian cattle with other

348 African cattle populations (Table S6). On the other hand, although majority of variation can be

349 explained within a population at individual level, the variation has always been nonsignificant

350 reflecting lack of genetic structuring. This trend of unstructured matrilineal populations within

351 Africa has been reported consistently throughout the entire continent (Alvarez et al., 2017). One of

352 the possible reasons could have been due to the influx of a continual zebu introgression especially 
353 following the great rinderpest disease that wiped out nearly 5.2 million head of cattle (Hanotte et 354 al., 2000, 2002). Nonetheless, the hybridization process between zebu and taurine which is 355 practiced throughout the continent, might somewhat explain this unstructured scenario. This is 356 usually attributed by the need of farmers to have a breed of cattle that can have both of the genetic 357 attribute including resistance to disease such as trypanosomiasis and at the same time to be 358 capable to withstand adverse tropical environmental conditions such as drought or hot or humid 359 climatic environments (Kim et al., 2017).

360 We also observed similar genetic diversity pattern based on Y-chromosome analysis where the

361 haplotype diversity detected was higher compared to that observed in a previous study (Perez362 Pardal et al., 2018) for Nigerian cattle possibly due to a single breed population sampled, albeit it 363 was similar to haplotype diversity of cattle from India and Central Asia (Perez-Pardal et al., 364 2018). Generally, in comparison with other cattle populations in Africa, our study indicated the 365 highest genetic diversity of $1.000 \pm 0.016$ with the lowest in Zebu_Peul breed population from 366 Burkina Faso (Table S9). Nigerian male cattle samples have been observed with high genetic 367 diversity extrapolated by Y-chromosomal single nucleotide polymorphic marker which is 368 consistent with the scenario of the unique zebu alleles mostly found only in West Africa (Pereze369 Pardal et al., 2010, 2018). This was hypothesized by these authors that zebus in West Africa have 370 got unique genetic background probably because of genetic contribution from local ancient 371 humped cattle. However, even though recent zebu introgression could have occurred into this 372 region, may have not contributed much to the genetic affinity with other zebus from elsewhere 373 possibly because the introgressions were female mediated (Hanotte et al., 2000) which can also be 374 described in the case of Kuri cattle samples of Lake Chad (Meghen et al., 2000) or perhaps the 375 restocking of African zebu sires from East to West during the early $20^{\text {th }}$ century was relatively low 
376 (Alvarez et al., 2017). The high genetic divergence between zebu of West Africa and those from

377 Asia was recently unveiled by Pereze-Pardal et al. (2018) which further strengthens this

378 speculative hypothesis.

379 The present-day zebu-like cattle in West Africa were products of crossbreeding events between 380 the West African taurine cattle such as N'Dama and imported zebu cattle directly from Asia 381 (MacHugh et al. 1997; Kim et al., 2017) or rather indirectly with zebu from East Africa. We 382 computed the genetic relationships among Nigerian cattle by using MJ network (Fig. 1b) and NJ 383 tree (Fig. S1). We observed all Nigerian cattle to be exclusively of taurine T1, an African specific 384 haplogroup, and morphological resemblance of $B$. indicus such as the presence of the humps. This 385 scenario is in accordance with similar observations by Loftus et al. (1994a) but also a similar case 386 was depicted in zebu breeds of the Americas where they were typically found with mitochondrial 387 taurine haplogroup in their genomes (Ginja et al., 2019). These observations further explain that 388 zebu introgression is typically male-mediated and that this scenario took place in many places 389 around the globe. In the light of this argument with respect to Nigerian cattle in West Africa, most 390 farmers in this region preferred zebu of male lineage due to their massive muscle size but also

391 being resistant to rinderpest that taurines are not, even though them being less vigorous towards 392 trypanosomiasis, a disease prevalent in tsetse regions of both West and Central Africa whereby 393 taurine cattle depict resistance to the disease (Grigson, 1991; Ibeagha-Awemu et al., 2004) The 394 complete absence of Asian zebu mtDNA in Nigerian cattle samples suggests that crossbreeding 395 events were mainly through the imported Asian male zebus (Loftus et al., 1994a; Loftus et al., 396 1994b; Bradley et al., 1996). Nonetheless, this scenario could have been attributed by the 397 continued adoption of trypanotolerant breeds that probably led to total loss of the $B$. indicus 398 mtDNA lineages or its vulnerability towards population bottleneck. This has also been observed 
399 elsewhere by several studies particularly cattle from North-East Asia (Mannen et al., 2004). 400 Bradley et al. (1994) and Perez-Pardal et al. (2018) further stress this observation extrapolating 401 the importation of probably only male zebus into West African region. Other factors such as 402 droughts and the great rinderpest disease outbreak or unbiased selection of cattle breeds over zebu 403 mitochondria may have contributed to the loss of any rare zebu mtDNA (Dadi et al., 2009).

404 We have also analyzed the Nigerian cattle using a single Y-chromosomal polymorphic marker in 405 the X-degenerate region of the male specific Y-chromosome region. Our findings based on 406 mtDNA and Y-chromosome analyses conducted in this study have confirmed that Nigerian cattle 407 are an influence of both taurine and zebu lineages from female and male genetic contributions 408 respectively, with only zebu male specific haplotypes being detected. This illustrates a complex 409 scenario of the genetic background in most of the present-day African cattle populations (Alvarez 410 et al., 2017). Previously, mtDNA studies (Loftus et al., 1994a) found that African cattle are of 411 taurine background. However, earlier studies conducted using Y-chromosomal markers (Bradley 412 et al., 1994) found that African cattle had been genetically introgressed with zebu cattle from Asia. 413 The introgressions were male mediated (Hanotte et al., 2000) and that majority of African cattle 414 belong to the zebu specific haplogroup Y3. Patrilineal studies show that zebu cattle are distributed 415 at varying frequency across the continent with more frequency observed in eastern and Central 416 Africa but at a lower frequency in the western and southern parts of Africa (Fig. S3). This 417 decrease in frequency of zebu haplogroup Y3 as one moves towards West and South of Africa is 418 possibly due to the presence of B. taurus European haplogroups Y1 and Y2 in these regions (Fig. 419 S3). A study by Decker et al. (2014) had previously demonstrated similar observations using 420 autosomal single nucleotide polymorphisms (SNPs) markers. This unevenly distribution of zebu 421 allele and introgression in the African continent is possibly attributed to selection of breeds by 
422 farmers based on disease tolerance such as tolerance to trypanosomiasis or ability to withstand 423 adverse environmental conditions such as drought (Hanotte et al., 2000). Although, some of the 424 previous studies conducted in West African cattle detected European Y1/Y2 haplogroups (Perez425 Pardal et al., 2010; Ginja et al., 2019), it is surprisingly enough that our study samples from 426 Nigeria did not yield any of these, but rather showed that all Nigerian cattle are of zebu Y3 origin. 427 We believe that, the undetected Y1 or Y2 haplotypes in Nigerian cattle might possibly indicate 428 low or no influence of European cattle in these studied samples, coinciding with what was 429 reported previously by Hanotte et al. (2000) of 0\% Y-chromosomal taurine alleles in Nigerian 430 cattle. Nonetheless, it's probable that our sampling coverage did not cover enough samples from 431 western part of Nigeria where most cattle of haplotype Y1 and Y2 are likely to be found.

432 Similarly, this was shown in phylogenetic tree (Fig. S4), where Nigerian cattle somehow clustered 433 separately from European Y1/Y2 haplotypes. Some studies based on additional Y-chromosomal 434 markers, including STRs, have further indicated that B. indicus haplogroup Y3 is composed of 435 three sub-haplotype families which include $\mathrm{Y} 3_{\mathrm{A}}, \mathrm{Y} 3_{\mathrm{B}}$ (also defined as $\mathrm{Y} 3 \mathrm{~b}$ nomenclature), and $436 \mathrm{Y}_{\mathrm{C}}$ (or Y3a) (Chen et al., 2018; Perez-Pardal et al., 2018), with Y3 ${ }_{\mathrm{A}}$ being a cosmopolitan 437 haplotype, while $\mathrm{Y} 3_{\mathrm{B}}$ is exclusively found in West African cattle. These three haplotypic zebu 438 families co-existed together with their counterpart taurine in approximately 200,000 years ago 439 (Loftus et al., 1994a; Ho et al., 2008; Murray et al., 2010). However, they diverged at different 440 times among themselves before the start of domestication, with the most recent divergence 441 occurring between West and East African zebus (Perez-Pardal et al., 2018).

442 Moreover, our study observed that the Nigerian cattle of Y3 haplogroup can be further classified 443 into sub-haplotype family Y3b based on the nomenclature adopted by Chen et al. (2018) 444 (Supplementary Data S1) with several zebu strains (Fig. 2) which possibly reflect less intensive 
445 selection in African countries as observed in Nigeria compared to other regions for instance

446 Europe (Xu et al 2015). Our findings indicate a possibility of gene flow or backcrossing of cattle

447 with wild stock from other related bovine species which may have had occurred probably during

448 initial stages of early domestication in the Eurasia prior to population expansion or at later

449 instances post domestication around 2000 years ago (Chen et al., 2010; Perez-Pardal et al., 2018).

450 These possible imprints of gene flow or introgression with wild stock or other related domestic

451 Bovidae was inferred through the shared matrilineal mutation motifs in the wild bison (Bison

452 bison), the domestic yak (B. grunniens) and Nigerian cattle. This was clearly confirmed by the

453 patrilineal phylogeny where some of the Nigerian cattle clustered closely with yak, the $B$.

454 grunniens and B. bison (Fig. S4). Our finding is coherent with a study by Chen et al. (2018),

455 where they were able to detect evidence of gene flow and adaptive introgression between Chinese

456 zebu cattle and the Banteng (B. javanicus). Nonetheless, previous studies have also reported

457 possibility of secondary introgression events that might have occurred from the wild oxen stock

458 into the gene pool of domestic cattle during early domestication (Achilli et al., 2008, 2009). The

459 observed shared wild stock mutations in Nigerian cattle agrees with previous studies (Perez-

460 Pardal et al., 2010, 2018) that the $\mathrm{Y} 3_{\mathrm{B}}$, also termed $\mathrm{Y} 3 \mathrm{~b}$ (by Chen et al., 2018) zebu lineage in

461 West Africa were probably intermingled with ancient humped cattle which would currently be a

462 significant representative reservoir of male zebu biodiversity. The legacy of the possibility of

463 subsequent introgression from local ancient wild cattle partly explains the existing large

464 divergence between West African zebus and zebus from Asia (Perez-Pardal et al., 20 10, 2018).

465 These observations maybe speculative, and could indicate a much more complex scenario of the

466 origin of cattle that possibly involved multiple ancestral domestication populations (Perez-Pardal

467 et al., 2018) especially when considering the discrete contribution of wild ox into the gene pools 
468 of the major descendant lineages of cattle (Murray et al., 2010) or perhaps the remnant traces left

469 before the divergence between domestic Bos species and the ancient wild ox had taken place some 470 million years ago (Buntjer et al., 2002).

471

472 CONCLUSIONS

473 This study reported the current genetic status and some possible new insights about the origin of 474 cattle in West Africa using Nigerian samples from matrilineal and patrilineal perspectives. High 475 level of maternal and paternal genetic diversity was observed in Nigerian cattle, with lack of 476 phylogeographic structure possibly due to human mediated interventions that usually enhance 477 severe intermixing as a result of improper husbandry management practices. The phylogenetic 478 tree based on patrilineal analysis and the matrilineal haplogroup classification have both 479 provided consensus evidence of a possible introgression and gene flow from wild ancient stock 480 and other related bovine species into Nigerian cattle. We recommend carrying out in-depth 481 population genetic studies using high-throughput technologies on complete mtDNA and 482 autosomal genomes of Nigerian cattle in West Africa as well as the use of other Y-chromosomal 483 markers in order to generate comprehensive genetic information on their adaptive traits, selection 484 and demographic history.

\section{Authors' contributions}

Y.-P.Z., D.H.M, A.C.A. and M.-S.P. led the project, and designed and conceived the study.

D.H.M. and A.C.A. prepared the manuscript. M.-S.P. and Y.-P.Z. revised the manuscript. 
490 G.F.M. performed sampling. D.H.M. carried out experiments. All authors revised and approved 491 the final manuscript.

492

493 Acknowledgments

494 We appreciate all those who assisted in the study. This work was supported by the Sino-Africa 495 Joint Research Center, Chinese Academy of Sciences (SAJC201611) and the Animal Branch of 496 the Germplasm Bank of Wild Species, Chinese Academy of Sciences (the Large Research 497 Infrastructure Funding). The Chinese Academy of Sciences President's International Fellowship 498 Initiative provided support to Adeniyi Charles Adeola (2018FYB0003). David Heriel Mauki and 499 Said Ismael Ng'ang'a acknowledge the support of the Chinese Academy of Sciences-The World 500 Academy of Sciences (CAS-TWAS) President's Fellowship Program for Doctoral students.

501

502 Competing interests

503 The authors declare that they have no competing interests.

504

505

\section{References}

Achilli A, Bonfiglio S, Olivieri A, Malusa A, Pala M, Hooshiar Kashani B, Perego UA, AjmoneMarsan P, Liotta L, Semino O, Bandelt HJ, Ferretti L, and Torroni A. 2009. The multifaceted origin of taurine cattle reflected by the mitochondrial genome. PLoS ONE 4(6). e5753. 10.1371/journal.pone.0005753 
510 Achilli A, Olivieri A, Pellecchia M, Uboldi C, Colli L, Al-Zahery N, Accetturo M, Pala M, 511 Hooshiar Kashani B, Perego UA, Battaglia V, Fornarino S, Kalamati J, Houshmand M,

512

513

514

515

516

517

518

519

520

521

522

523

524

525

526

527

528

529

530

Negrini R, Semino O, Richards M, Macaulay V, Ferretti L, Bandelt HJ, Ajmone-Marsan P, and Torroni A. 2008. Mitochondrial genomes of extinct aurochs survive in domestic cattle. Current Biology 18(4):R157-158. 10.1016/j.cub.2008.01.019

Álvarez I, Pérez - Pardal L, Traoré A, Koudandé DO, Fernández I, Soudré A, and Goyache F. 2017. Differences in genetic structure assessed using Y - chromosome and mitochondrial DNA markers do not shape the contributions to diversity in African sires. Journal of Animal Breeding and Genetics 134(5):393-404.

Anderson S, de Bruijn MH, Coulson AR, Eperon IC, Sanger F, and Young IG. 1982. Complete sequence of bovine mitochondrial DNA. Conserved features of the mammalian mitochondrial genome. Journal of molecular biology 156(4):683-717. 10.1016/00222836(82)90137-1

Bandelt HJ, Forster P, and Rohl A. 1999. Median-joining networks for inferring intraspecific phylogenies. Molecular Biology and Evolution 16:37-48. 10.1093/oxfordjournals.molbev.a026036

Beja-Pereira A, Caramelli D, Lalueza-Fox C, Vernesi C, Ferrand N, Casoli A, Goyache F, Royo LJ, Conti S, Lari M, Martini A, Ouragh L, Magid A, Atash A, Zsolnai A, Boscato P, Triantaphylidis C, Ploumi K, Sineo L, Mallegni F, Taberlet P, Erhardt G, Sampietro L, Bertranpetit J, Barbujani G, Luikart G, and Bertorelle G. 2006. The origin of European cattle: evidence from modern and ancient DNA. Proceedings of the National Academy of 
532 Bonfiglio S, Achilli A, Olivieri A, Negrini R, Colli L, Liotta L, Ajmone-Marsan P, Torroni A, and 533 Ferretti L. 2010. The enigmatic origin of bovine mtDNA haplogroup R: sporadic 534 interbreeding or an independent event of Bos primigenius domestication in Italy? PLoS 535 ONE 5(12). e15760. 10.1371/journal.pone.0015760

536

537

538

539

540

541

542

543

544

545

546

547

548

Bonfiglio S, De Gaetano A, Tesfaye K, Grugni V, Semino O, Ferretti L. 2012b. A novel USP9Y polymorphism allowing a rapid and unambiguous classification of Bos taurus $\mathrm{Y}$ chromosomes into haplogroups. Animal Genetics 43(5): 611-613.

Bonfiglio S, Ginja C, De Gaetano A, Achilli A, Olivieri A, Colli L, Tesfaye K, Agha SH, Gama LT, Cattonaro F, Penedo MC, Ajmone-Marsan P, Torroni A, and Ferretti L. 2012a. Origin and spread of Bos taurus: new clues from mitochondrial genomes belonging to haplogroup T1. PLoS One 7(6). e38601. 10.1371/journal.pone.0038601

Bradley DG, Loftus RT, Cunningham P, and MacHugh DE. 1998. Genetics and domestic cattle origins. Evolutionary Anthropology: Issues, News, and Reviews 6:79-86. 10.1002/(sici)1520-6505(1998)6:3<79::aid-evan2>3.0.co;2-r

Bradley DG, MacHugh DE, Cunningham P, and Loftus RT. 1996. Mitochondrial diversity and the origins of African and European cattle. Proceedings of the National Academy of Sciences of the United States of America 93:5131-5135. 10.1073/pnas.93.10.5131

Bradley DG, MacHugh DE, Loftus RT, Sow RS, Hoste CH, and Cunningham EP. 1994. Zebutaurine variation in Y chromosomal DNA: a sensitive assay for genetic introgression in west African trypanotolerant cattle populations. Animal Genetics 25:7-12. 
552 Buntjer JB, Otsen M, Nijman IJ, Kuiper MT, and Lenstra JA. 2002. Phylogeny of bovine species

553 based on AFLP fingerprinting. Heredity 88(1):46-51. 10.1038/sj.hdy.6800007

554 Chang TC, Yang Y, Retzel EF, and Liu WS. 2013. Male-specific region of the bovine Y 555 chromosome is gene rich with a high transcriptomic activity in testis development. 556 Proceedings of the National Academy of Sciences of the United States of America

558

559

560

561

562

563

564

565

566

567

568

569

570

571

572 110:12373-12378. 10.1073/pnas.1221104110

Chen N, Cai Y, Chen Q, Li R, Wang K, Huang Y, Hu S, Huang S, Zhang H, Zheng Z, Song W, Ma Z, Ma Y, Dang R, Zhang Z, Xu L, Jia Y, Liu S, Yue X, Deng W, Zhang X, Sun Z, Lan X, Han J, Chen H, Bradley DG, Jiang Y, and Lei C. 2018. Whole-genome resequencing reveals world-wide ancestry and adaptive introgression events of domesticated cattle in East Asia. Nature Communications 9(1):2337. 10.1038/s41467-018-04737-0

Chen S, Lin BZ, Baig M, Mitra B, Lopes RJ, Santos AM, Magee DA, Azevedo M, Tarroso P, Sasazaki S, Ostrowski S, Mahgoub O, Chaudhuri TK, Zhang YP, Costa V, Royo LJ, Goyache F, Luikart G, Boivin N, Fuller DQ, Mannen H, Bradley DG, and Beja-Pereira A. 2010. Zebu cattle are an exclusive legacy of the South Asia neolithic. Mol Biology and Evolution 27(1):1-6. 10.1093/molbev/msp213

Dadi H, Tibbo M, Takahashi Y, Nomura K, Hanada H, and Amano T. 2009. Variation in mitochondrial DNA and maternal genetic ancestry of Ethiopian cattle populations. Animal Genetics 40(4):556-559. 10.1111/j.1365-2052.2009.01866.x

Decker JE, McKay SD, Rolf MM, Kim J, Molina Alcala A, Sonstegard TS, Hanotte O, Gotherstrom A, Seabury CM, Praharani L, Babar ME, Correia de Almeida Regitano L, 
573

574

575

576

577

578

579

580

581

582

583

584

585

586

587

588

589

590

591

592

593

Yildiz MA, Heaton MP, Liu WS, Lei CZ, Reecy JM, Saif-Ur-Rehman M, Schnabel RD, and Taylor JF. 2014. Worldwide patterns of ancestry, divergence, and admixture in domesticated cattle. PLoS Genetics 10(3). e1004254. 10.1371/journal.pgen.1004254

Excoffier L, and Lischer HE. 2010. Arlequin suite ver 3.5: a new series of programs to perform population genetics analyses under Linux and Windows. Molecular Ecology Resources 10:564-567. 10.1111/j.1755-0998.2010.02847.x

Felsenstein J. 1985. Confidence limits on phylogenies: An approach using the bootstrap. Evolution 39:783-791.

Freeman AR, Meghen CM, MacHugh DE, Loftus RT, Achukwi MD, Bado A, Sauveroche B, and Bradley DG. 2004. Admixture and diversity in West African cattle populations. Molecular Ecology 13:3477-3487. 10.1111/j.1365-294X.2004.02311.x

Fu YX. 1997. Statistical tests of neutrality of mutations against population growth, hitchhiking and background selection. Genetics 147:915-925.

Gifford-Gonzalez D, and Hanotte O. 2011. Domesticating Animals in Africa: Implications of Genetic and Archaeological Findings. Journal of World Prehistory 24:1-23. $10.1007 / \mathrm{s} 10963-010-9042-2$

Ginja C, Gama LT, Cortes O, Burriel IM, Vega-Pla JL, Penedo C, Sponenberg P, Canon J, Sanz A, do Egito AA, Alvarez LA, Giovambattista G, Agha S, Rogberg-Munoz A, Lara MAC, BioBovis C, Delgado JV, and Martinez A. 2019. The genetic ancestry of American Creole cattle inferred from uniparental and autosomal genetic markers. Scientific Reports 9(1):11486. 10.1038/s41598-019-47636-0 
594 Ginja C, Penedo MCT, Melucci L, Quiroz J, Martinez Lopez OR, Revidatti MA, Gama LT. 2010.

595

596

597

598

599

600

601

602

603

604

605

606

607

608

609

610

611

612

613

614 Origins and genetic diversity of New World Creole cattle: inferences from mitochondrial and Y chromosome polymorphisms. Animal genetics 41(2): 128-141.

Ginja C, Telo da Gama L, and Penedo MC. 2009. Y chromosome haplotype analysis in Portuguese cattle breeds using SNPs and STRs. Journal of Heredity 100(2):148-157. 10.1093/jhered/esn080

Götherström A, Anderung C, Hellborg L, Elburg R, Smith C, Bradley DG, and Ellegren H. 2005. Cattle domestication in the Near East was followed by hybridization with aurochs bulls in Europe. Proceedings of the Royal Society B: Biological Sciences 272(1579):2345-2350. $10.1098 / \mathrm{rspb} .2005 .3243$

Grigson C. 1991. An African Origin for African Cattle? Some Archaeological Evidence. The African Archaeological Review 9:119-144.

Hanotte O, Bradley DG, Ochieng JW, Verjee Y, Hill EW, and Rege JE. 2002. African pastoralism: genetic imprints of origins and migrations. Science 296(5566):336-339. 10.1126/science. 1069878

Hanotte O, Tawah CL, Bradley DG, Okomo M, Verjee Y, Ochieng J, and Rege JRO. 2000. Geographic distribution and frequency of a taurine Bostaurus and an indicine Bos indicus Y specific allele amongst sub-Saharan African cattle breeds. Molecular Ecology 9(4):387396.

Harpending HC. 1994. Signature of ancient population growth in a low-resolution mitochondrial DNA mismatch distribution. Human Biology 66:591-600. 
615 Hiendleder S, Lewalski H, and Janke A. 2008. Complete mitochondrial genomes of Bos taurus 616 and Bos indicus provide new insights into intra-species variation, taxonomy and domestication. Cytogenetic and Genome Research 120(1-2):150-156.

618

619

620

621

622

623

624

625

626

Horsburgh KA, Prost S, Gosling A, Stanton JA, Rand C, and Matisoo-Smith EA. 2013. The genetic diversity of the Nguni breed of African Cattle (Bos spp.): complete mitochondrial genomes of haplogroup T1. PLoS One 8(8):e71956. 10.1371/journal.pone.0071956

Huang C, Zhang Q, Fu D, Basang W, Chu M, Yangla D, Wu X, Ma X, Guo X, Yan P, and Liang C. 2020. The complete mitochondrial genome sequence and phylogenetic analysis of Sibu yak (Bos grunniens). Mitochondrial DNA Part B 5:46-47.

Ibeagha-Awemu EM, Jann OC, Weimann C, and Erhardt G. 2004. Genetic diversity, introgression and relationships among West/Central African cattle breeds. Genetics Selection Evolution 36(6):673-690. 10.1051/gse:2004024

Kim J, Hanotte O, Mwai OA, Dessie T, Bashir S, Diallo B, Agaba M, Kim K, Kwak W, Sung S, Seo M, Jeong H, Kwon T, Taye M, Song KD, Lim D, Cho S, Lee HJ, Yoon D, Oh SJ, Kemp S, Lee HK, and Kim H. 2017. The genome landscape of indigenous African cattle. Genome Biology 18(1): 1-14. 10.1186/s13059-017-1153-y

Kim K, Kwon T, Dessie T, Yoo D, Mwai OA, Jang J, Sung S, Lee S, Salim B, Jung J, Jeong H, Tarekegn GM, Tijjani A, Lim D, Cho S, Oh SJ, Lee H, Kim J, Jeong C, Kemp S, Hanotte O, Kim H. 2020.The mosaic genome of indigenous African cattle as a unique genetic resource for African pastoralism. Nature Genetics 1-12. https://doi.org/10.1038/s41588020-0694-2Kumar S, Stecher G, Li M, Knyaz C, Tamura K. 2018. MEGA X: Molecular 

Evolution 35:1547-1549.

638

639

640

641

642

643

644

645

646

647

648

649

650

651

652

653

654

655

Lai SJ, Liu YP, Liu YX, Li XW, Yao YG. 2006. Genetic diversity and origin of Chinese cattle revealed by mtDNA D-loop sequence variation. Molecular Phylogenetics and Evolution 38(1):146-154.

Lawson LJ, and Hewitt GM. 2002. Comparison of substitution rates in ZFX and ZFY introns of sheep and goat related species supports the hypothesis of male-biased mutation rates. Journal of Molecular Evolution 54(1):54-61. 10.1007/s00239-001-0017-x

Librado P, and Rozas J. 2009. DnaSP v5: a software for comprehensive analysis of DNA polymorphism data. Bioinformatics 25:1451-1452. 10.1093/bioinformatics/btp187

Lindgren G, Backstrom N, Swinburne J, Hellborg L, Einarsson A, Sandberg K, Cothran G, Vila C, Binns M, and Ellegren H. 2004. Limited number of patrilines in horse domestication. Nature genetics 36(4):335-336. 10.1038/ng1326

Loftus RT, MacHugh DE, Bradley DG, Sharp PM, and Cunningham P. 1994a. Evidence for two independent domestications of cattle. Proceedings of the National Academy of Sciences of the United States of America 91:2757-2761. 10.1073/pnas.91.7.2757

Loftus RT, MacHugh DE, Ngere LO, Balain DS, Badi AM, Bradley DG, and Cunningham EP. 1994b. Mitochondrial genetic variation in European, African and Indian cattle populations. Anim Genetics 25:265-271. 10.1111/j.1365-2052.1994.tb00203.x

MacHugh DE, Shriver MD, Loftus RT, Cunningham P, and Bradley DG. 1997. Microsatellite 
656

657

658

659

660

661

662

663

664

665

666

667

668

669

670

671

672

673

674

675

DNA variation and the evolution, domestication and phylogeography of taurine and zebu cattle (Bos taurus and Bos indicus). Genetics 146:1071-1086.

Magnavita C. 2006. Ancient humped cattle in Africa: a view from the Chad Basin. African Archaeological Review 23(3-4): 55-84.

Mannen H, Kohno M, Nagata Y, Tsuji S, Bradley DG, Yeo JS, Nyamsamba D, Zagdsuren Y, Yokohama M, Nomura K, and Amano T. 2004. Independent mitochondrial origin and historical genetic differentiation in North Eastern Asian cattle. Molecular Phylogenetics and Evolution 32:539-544. 10.1016/j.ympev.2004.01.010

Marshall F, and Hildebrand E. 2002. Cattle before crops: the beginnings of Food production in Africa. Journal of World Prehistory 16:99-143.

Meghen C, MacHugh DE, and Bradley DG. 1994. Genetic characteristics of West African cattle. World Animal Review 78:59-66.

Meghen C, MacHugh D, Sauveroche B, Kana G, Bradley D. 2000. Characterization of the Kuri cattle of Lake Chad using molecular genetic techniques. The origins and development of African Livestock: Archaeology, genetics, linguistics and ethnography 259-268.

Murray C, Huerta-Sanchez E, Casey F, and Bradley DG. 2010. Cattle demographic history modelled from autosomal sequence variation. Philosophical Transactions of the Royal Society B: Biological Sciences 365(1552):2531-2539. 10.1098/rstb.2010.0103

Nijman IJ, Van Boxtel DC, Van Cann LM, Marnoch Y, Cuppen E, and Lenstra JA. 2008. Phylogeny of Y chromosomes from bovine species. Cladistics 24(5):723-726.

Peer] reviewing PDF | (2020:06:50178:2:1:NEW 26 Nov 2020) 
676 Olivieri A, Gandini F, Achilli A, Fichera A, Rizzi E, Bonfiglio S, Battaglia V, Brandini S, De 677 Gaetano A, El-Beltagi A, Lancioni H, Agha S, Semino O, Ferretti L, and Torroni A. 2015. 678 Mitogenomes from Egyptian Cattle Breeds: New Clues on the Origin of Haplogroup Q and 679 the Early Spread of Bos taurus from the Near East. PLoS ONE 10(10):e0141170. 680 10.1371/journal.pone.0141170

681 682 683

Peng MS, Fan L, Shi NN, Ning T, Yao YG, Murphy RW, Wang WZ, and Zhang YP. 2015. DomeTree: a canonical toolkit for mitochondrial DNA analyses in domesticated animals. Molecular Ecology Resources 15:1238-1242. 10.1111/1755-0998.12386

Perez-Pardal L, Royo LJ, Beja-Pereira A, Chen S, Cantet RJ, Traore A, Curik I, Solkner J, Bozzi R, Fernandez I, Alvarez I, Gutierrez JP, Gomez E, Ponce de Leon FA, and Goyache F. 2010. Multiple paternal origins of domestic cattle revealed by Y-specific interspersed multilocus microsatellites. Heredity 105(6):511-519. 10.1038/hdy.2010.30

Perez-Pardal L, Sanchez-Gracia A, Alvarez I, Traore A, Ferraz JBS, Fernandez I, Costa V, Chen S, Tapio M, Cantet RJC, Patel A, Meadow RH, Marshall FB, Beja-Pereira A, and Goyache F. 2018. Legacies of domestication, trade and herder mobility shape extant male zebu cattle diversity in South Asia and Africa. Scientific Reports 8(1):18027. 10.1038/s41598-01836444-7

Ramirez O, Ojeda A, Tomas A, Gallardo D, Huang LS, Folch JM, Clop A, Sanchez A, Badaoui B, Hanotte O, Galman-Omitogun O, Makuza SM, Soto H, Cadillo J, Kelly L, Cho IC, Yeghoyan S, Perez-Enciso M, and Amills M. 2009. Integrating Y-chromosome, mitochondrial, and autosomal data to analyze the origin of pig breeds. Molecular Biology and Evolution 26(9):2061-2072. 10.1093/molbev/msp118 
698 Rege JEO. 1999. The state of African cattle genetic resources I. Classification framework and

699

700

701

702

703

704

705

706

707

708

709

710

711

712

713

714

715

716

717 identification of threatened and extinct breeds. FAO/UNEP Animal Genetic Resources Information Bulletin 25:1-25.

Rogers AR, and Harpending H. 1992. Population growth makes waves in the distribution of pairwise genetic differences. Molecular Biology and Evolution 9:552-569. 10.1093/oxfordjournals.molbev.a040727

Saitou N, and Nei M. 1987. The neighbor-joining method: a new method for reconstructing phylogenetic trees. Molecular Biology and Evolution 4(4):406-425. 10.1093/oxfordjournals.molbev.a040454

Sambrook J, and Russell DW. 2001. Molecular cloning. In: Laboratory CSH, ed. A laboratory manual. 3 ed. New York: Cold Spring Harbor Laboratory Press.

Tajima F. 1989. Statistical method for testing the neutral mutation hypothesis by DNA polymorphism. Genetics 123:585-595.

Tamura K, Nei M, Kumar S. 2004. Prospects for inferring very large phylogenies by using the neighbor-joining method. Proceedings of the National Academy of Sciences 101:1103011035.

Tarekegn GM, Tesfaye K, Mwai OA, Djikeng A, Dessie T, Birungi J, Osama S, Zergaw N, Alemu A, Achieng G, Tutah J, Mutai C, Njuguna J, and Mwacharo JM. 2018. Mitochondrial DNA variation reveals maternal origins and demographic dynamics of Ethiopian indigenous goats. Ecology and Evolution 8(3):1543-1553. 10.1002/ece3.3710

Peer) reviewing PDF | (2020:06:50178:2:1:NEW 26 Nov 2020) 
718 Thompson JD, Higgins DG, and Gibson TJ. 1994. CLUSTAL W: improving the sensitivity of 719 progressive multiple sequence alignment through sequence weighting, position-specific 720 gap penalties and weight matrix choice. Nucleic Acids Research 22(22):4673-4680. $10.1093 / \operatorname{nar} / 22.22 .4673$

722 Troy CS, MacHugh DE, Bailey JF, Magee DA, Loftus RT, Cunningham P, Chamberlain AT,

723

724

725

726

727

728

729

730

731

732

733

734

735

736

737

738

Sykes BC, and Bradley DG. 2001. Genetic evidence for Near-Eastern origins of European cattle. Nature 410:1088-1091. 10.1038/35074088

Verkaar EL, Nijman IJ, Beeke M, Hanekamp E, and Lenstra JA. 2004. Maternal and paternal lineages in cross-breeding bovine species. Has wisent a hybrid origin? Molecular Biology and Evolution 21 (7):1165-1170. 10.1093/molbev/msh064

Wang GD, Xie HB, Peng MS, Irwin D, and Zhang YP. 2014. Domestication genomics: evidence from animals. Annual Review of Animal Biosciences 2:65-84.

Xu L, Bickhart DM, Cole JB, Schroeder SG, Song J, Tassell CP, Sonstegard TS, Liu GE. 2015. Genomic signatures reveal new evidences for selection of important traits in domestic cattle. Molecular biology and evolution 32(3):711-725. https://doi.org/10.1093/molbev/msu333

\section{Figure legend}

Figure 1 Sampling locations of cattle in Nigeria and the network of 420 cattle samples based on 636 bp of the mtDNA D-loop region. (a) Map of cattle sampling locations in Nigeria (Zamfara, Kano, Katsina, Kaduna, and Sokoto from North West; Taraba and Plateau from North 
739 East/Central; and Oyo from the West) and the haplogroup distribution based on mtDNA across

740 Africa. The maps of Africa and Nigeria were generated by an online version of the SmartDraw

7412012 software (https://cloud.smartdraw.com/). (b) Median-joining network of 420 cattle samples

742 constructed by using NETWORK v 4.6 (Bandelt, Forster \& Rohl, 1999). Reference sequences

743 used for haplotype network analysis included: Europe, n=76 (Loftus et al., 1994a; Lai et al.,

744 2006; Achilli et al., 2008; Hiendleder, Lewalski \& Janke, 2008; Bonfiglio et al., $2012 a$ and

745 AF034438-AF034446 were retrieved from the GenBank); West Asia, n=16 (Achilli et al., 2008);

746 Egypt, n=31 (Bonfiglio et al., 2012a; Olivieri et al., 2015); Ethiopia, n=126 (Dadi et al., 2009;

747 Bonfiglio et al., 2012a); Mozambique, n=16 (JQ684029-JQ684045 were retrieved from the

748 GenBank), South Africa, $\mathrm{n}=34$ (Horsburgh et al., 2013) and two additional Nigerian samples

749 mined from GenBank (Accession no. L27731 and L27730). Sizes of the circles are proportional

750 to haplotype frequencies. $m$, refers to number of mutation steps and those not indicated are just

751 one step mutation. Colours indicate the geographical distribution of the sampling locations

752 across Africa, Europe and West Asia as shown by the legend in (b).

753

754

755

756

757

758

759

760

\section{Figure 2 The network of 28 cattle samples based on 286 bp of the ZFY Y-chromosome}

region. Sizes of the circles are proportional to haplotype frequencies and the number of mutation steps in each branch are given. Colours indicate the geographical distribution of the samples as follows: Dark green, Nigeria; Orange, Asia; and Blue, Europe. Source of the data for the Y haplogroups was retrieved from Nijman et al. 2008, Ginja, Telo da Gama \& Penedo, (2009), MF683853 and MF683854 were retrieved from the GenBank.

\section{Table legend}


761 Table 1 Genetic diversity of cattle in Africa based on mtDNA D-Loop

762 Table 2 Mutations that describe the distinction of the three major haplogroups of cattle based on

763 ZFY intron 10 gene. The two genomic sites that separate each distinct haplogroup are in bold.

764 The seven mutations observed in Nigerian cattle are italicized.

765

766 


\section{Table 1 (on next page)}

Genetic diversity of cattle in Africa based on mtDNA D-Loop 
1 Table 1. Genetic diversity of cattle in Africa based on mtDNA D-Loop

2

\begin{tabular}{|c|c|c|c|c|c|c|}
\hline Population & $\mathbf{N}$ & PS & $\mathbf{H}$ & HD (SD) & $\pi(\mathrm{SD})$ & Df \\
\hline 1. Nigeria & 119 & 67 & 80 & $0.985(0.005)$ & $0.051(0.029)$ & 3.403 \\
\hline (a) North West ${ }^{1}$ & 62 & 44 & 44 & $0.984(0.007)$ & $0.076(0.044)$ & 3.338 \\
\hline (b) North East $/$ Central ${ }^{2}$ & 56 & 52 & 43 & $0.983(0.009)$ & $0.067(0.038)$ & 3.462 \\
\hline (c) $\mathrm{West}^{3}$ & $3 *$ & 4 & 3 & $1.000(0.272)$ & $0.667(0.598)$ & 2.667 \\
\hline 2. Egypt & 31 & 46 & 30 & $1.000(0.082)$ & $0.010(0.005)$ & 6.391 \\
\hline 3. Mozambique & 16 & 18 & 15 & $0.992(0.025)$ & $0.180(0.109)$ & 3.233 \\
\hline 4. Ethiopia & 126 & 70 & 83 & $0.969(0.009)$ & $0.005(0.003)$ & 3.365 \\
\hline 5. South Africa & 34 & 17 & 24 & $0.961(0.019)$ & $0.006(0.003)$ & 3.606 \\
\hline
\end{tabular}

3

4 Note: $\mathrm{N}=$ sample size, $\mathrm{PS}=$ the number of polymorphic sites, $\mathrm{H}=$ the number of haplotypes, $\mathrm{HD}$

5 = haplotype diversity, $\pi=$ nucleotide diversity, $\mathrm{Df}=$ the mean number of nucleotide differences,

6 and $\mathrm{SD}=$ standard deviations. ${ }^{1}$ Cattle samples from Zamfara, Kano, Katsina, Kaduna and Sokoto

7 States; ${ }^{2}$ Samples from Taraba and Jos, Plateau States; ${ }^{3}$ Samples from Ibadan, Oyo State. *Two

8 additional downloaded samples from GenBank (Accession no. L27731 and L27730). The

9 estimation of haplotype and nucleotide diversity based on $636 \mathrm{bp}$ mtDNA D-loop sequence was carried out by ARLEQUIN v. 3.5 (Excoffier \& Lischer, 2010) software. 


\section{Table 2 (on next page)}

Mutations that describe the distinction of the three major haplogroups of cattle based on ZFY intron 10 gene. The two genomic sites that separate each distinct haplogroup are in bold. The seven mutations observed in Nigerian cattle are italicized. 
1 Table 2. Mutations that describe the distinction of the three major haplogroups of cattle based on

2 ZFY intron 10 gene. The two genomic sites that separate each distinct haplogroup are in bold.

3 The seven mutations observed in Nigerian cattle are italicized.

\begin{tabular}{|c|c|c|c|}
\hline \multicolumn{4}{|c|}{ ZFY intron 10} \\
\hline Haplogroup & Reference & Alternative & Publication \\
\hline \multirow[t]{2}{*}{ Y1 } & $\mathrm{C}$ & $\mathrm{C}$ & \\
\hline & GT & -- & \\
\hline \multirow[t]{2}{*}{$\mathrm{Y} 2$} & $\mathrm{C}$ & $\mathbf{C}$ & Gotherstrom et al. 2005 \\
\hline & GT & GT & Ginja et al. 2009 \\
\hline \multirow[t]{2}{*}{ Y3 } & $\mathrm{C}$ & $\mathbf{T}$ & \\
\hline & GT & GT & \\
\hline \multirow[t]{2}{*}{ Y3 } & $\mathrm{C}$ & $\mathrm{T}$ & \\
\hline & GT & GT & \\
\hline g.797 & $A$ & $G$ & \\
\hline g.786 & $A$ & $T$ & \\
\hline g. 800,804 & $A$ & $C$ & This study \\
\hline g. $784,803,803$ & $T$ & $A$ & \\
\hline g. 802,805 & $T$ & $G$ & \\
\hline g. $802,803,804$ & $T$ & $C$ & \\
\hline g.801 & $C$ & $T$ & \\
\hline
\end{tabular}

4 


\section{Figure 1}

Sampling locations of cattle in Nigeria and the network of 420 cattle samples based on $636 \mathrm{bp}$ of the mtDNA D-loop region.

\section{Sampling locations of cattle in Nigeria and the network of 420 cattle samples} based on 636 bp of the mtDNA D-Ioop region. (a) Map of cattle sampling locations in Nigeria (Zamfara, Kano, Katsina, Kaduna, and Sokoto from North West; Taraba and Plateau from North East/Central; and Oyo from the West) and the haplogroup distribution based on mtDNA across Africa. The maps of Africa and Nigeria were generated by an online version of the SmartDraw 2012 software (https://cloud.smartdraw.com/). (b) Median-joining network of 420 cattle samples constructed by using NETWORK v 4.6 ( Bandelt, Forster \& Rohl, 1999 ) . Reference sequences used for haplotype network analysis included: Europe, $n=76$ (Loftus et al., 1994a; Lai et al., 2006; Achilli et al., 2008; Hiendleder, Lewalski \& Janke, 2008; Bonfiglio et al., 2012a and AF034438-AF034446 were retrieved from the GenBank); West Asia, n=16 (Achilli et al., 2008); Egypt, $\mathrm{n}=31$ (Bonfiglio et al., 2012a; Olivieri et al., 2015); Ethiopia, $\mathrm{n}=126$ (Dadi et al., 2009; Bonfiglio et al., 2012a); Mozambique, $\mathrm{n=16}$ (JQ684029-JQ684045 were retrieved from the GenBank), South Africa, $n=34$ (Horsburgh et al., 2013) and two additional Nigerian samples mined from GenBank (Accession no. L27731 and L27730). Sizes of the circles are proportional to haplotype frequencies. $m$, refers to number of mutation steps and those not indicated are just one step mutation. Colours indicate the geographical distribution of the sampling locations across Africa, Europe and West Asia as shown by the legend in (b). 

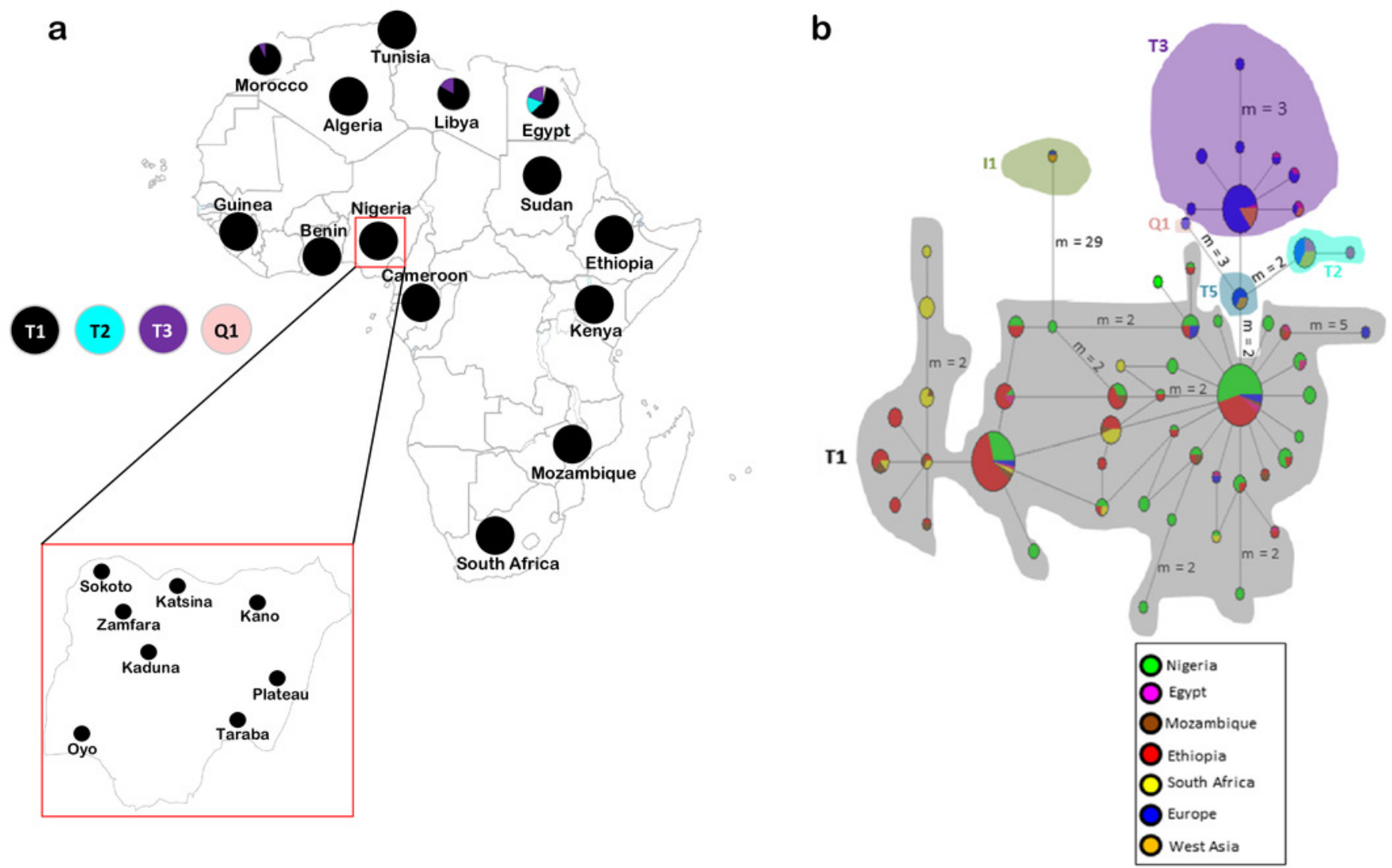
Figure 2

The network of 28 cattle samples based on 286 bp of the ZFY Y-chromosome region

Sizes of the circles are proportional to haplotype frequencies and the number of mutation

steps in each branch are given. Colours indicate the geographical distribution of the samples as follows: Dark green, Nigeria; Orange, Asia; and Blue, Europe. Source of the data for the $Y$ haplogroups was retrieved from Nijman et al. 2008, Ginja, Telo da Gama \& Penedo, (2009), MF683853, MF683854 were retrieved from the GenBank.

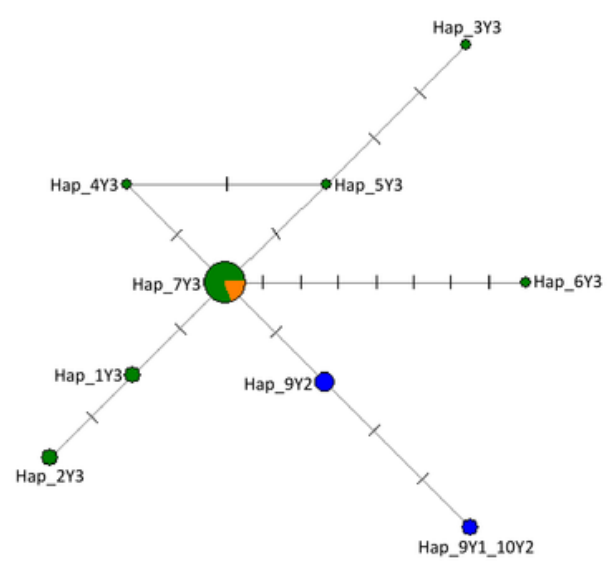

